\title{
GPR35 in Intestinal Diseases: From Risk Gene to Function
}

\author{
Berna Kaya ${ }^{1}$, Hassan Melhem ${ }^{1}$ and Jan Hendrik Niess ${ }^{1,2 *}$ \\ ${ }^{1}$ Department of Biomedicine, University of Basel, Basel, Switzerland, ${ }^{2}$ Department of Gastroenterology/Hepatology, Clarunis \\ - University Center for Gastrointestinal and Liver Diseases, Basel, Switzerland
}

Diet and gut microbial metabolites mediate host immune responses and are central to the maintenance of intestinal health. The metabolite-sensing G-protein coupled receptors (GPCRs) bind metabolites and trigger signals that are important for the host cell function, survival, proliferation and expansion. On the contrary, inadequate signaling of these metabolite-sensing GPCRs most likely participate to the development of diseases including inflammatory bowel diseases (IBD). In the intestine, metabolite-sensing GPCRs are highly expressed by epithelial cells and by specific subsets of immune cells. Such receptors provide an important link between immune system, gut microbiota and metabolic system. Member of these receptors, GPR35, a class A rhodopsin-like GPCR, has been shown to be activated by the metabolites tryptophan-derived kynurenic acid

OPEN ACCESS

Edited by:

Oscar Gilberto Gomez-Duarte, University at Buffalo, United States

Reviewed by: Jochen Mattner, University Hospital Erlangen, Germany Stefano Fiorucci, University of Perugia, Italy

*Correspondence: Jan Hendrik Niess janhendrik.niess@unibas.ch

Specialty section: This article was submitted to Microbial Immunology, a section of the journal Frontiers in Immunology

Received: 30 May 2021 Accepted: 18 October 2021 Published: 01 November 2021

Citation:

Kaya B, Melhem $\mathrm{H}$ and Niess $\mathrm{JH}$ (2021) GPR35 in Intestinal Diseases: From Risk Gene to Function.

Front. Immunol. 12:717392. doi: 10.3389/fimmu.2021.717392
(KYNA), the chemokine CXCL17 and phospholipid derivate lysophosphatidic acid (LPA) species. There have been studies on GPR35 in the context of intestinal diseases since its identification as a risk gene for IBD. In this review, we discuss the pharmacology of GPR35 including its proposed endogenous and synthetic ligands as well as its antagonists. We elaborate on the risk variants of GPR35 implicated in gut-related diseases and the mechanisms by which GPR35 contribute to intestinal homeostasis.

Keywords: GPR35, microbiota, metabolites, ligand-receptor interactions, risk variants, inflammatory bowel diseases

\section{INTRODUCTION}

The gastrointestinal tract is home to the vast majority of microbiota in the body most of which are colonized in the distal intestine (1). The gut microbiota consists of microorganisms including bacteria, viruses, parasites, and fungi. These microorganisms co-evolved with the host to form a symbiotic relationship. Intestinal microbiota is crucial for the regulation of the host metabolism and immunity. In turn, the intestinal immune system is tasked to establish tolerance towards the microbial community and to prevent pathogen invasion. The intestine is covered by an epithelial cell layer which forms a physical and biochemical barrier between the microbiota and the host (2). A compromised barrier integrity and/or dysregulated immune responses causes loss of tolerance to microbials and/or food antigens. This loss of tolerance is central to the pathogenesis of chronic intestinal disorders such as celiac disease, food allergies, and inflammatory bowel diseases (IBD) including Crohn's disease (CD) and ulcerative colitis (UC) in genetically susceptible individuals (3).

Since the incidence of IBD patients has rapidly increased in developing countries, it is unlikely that genetic factors alone are the main cause of rising rates of IBD (4). Thus, doubtlessly, environmental 
exposure significantly contributes to the development of IBD. Among environmental factors, dietary nutrients are increasingly recognized for their contribution to the pathogenesis of $\operatorname{IBD}(5,6)$. Specifically, a fiber-rich diet lowers risk of Crohn's disease whereas a "western" diet containing poly-unsaturated fatty acids, and transfats is associated with $\operatorname{IBD}(7,8)$. In this context, there is increasing evidence that host and/or microbiota-derived metabolites shape the host intestinal immune system by activating signaling cascades in epithelial and immune cells. These metabolites can evoke an immunological response through distinct pathways. Certain metabolites such butyrate and propionate can act as histone deacetylase inhibitors or transcriptional coactivators and thereby control gene expression intracellularly. In addition, dietary metabolites can signal via $\mathrm{G}$ protein-coupled receptors (GPCRs) (9). GPCRs can recognize host-derived metabolites such as medium- and long-chain fatty acids or secondary metabolites that undergo fermentation by the gut microbiota including fiber-derived short-chain fatty acids. Short-chain fatty acids such as butyrate, acetate, propionate, and nicotinic acid activate anti-inflammatory responses and bind to GPCRs including GPR41, GPR43 and GPR109A on epithelial and immune cells such as dendritic cells and regulatory T cells (10-12). Beside influencing host immunity and mucosal barrier integrity, dietary metabolites may affect the composition of the intestinal microbiota. This review focuses on the metabolites-sensing GPR35, which is a newly characterized receptor that profoundly affects the functions of immune and nonimmune cells in the intestine. we summarize and discuss the experimental findings emphasizing the importance of GPR35 in intestinal health and disease.

\section{G PROTEIN-COUPLED RECEPTOR (GPR) 35}

GPR35 is a rhodopsin-like, 7-transmembrane class A GPCR that was discovered in 1998 (13). The GPR35 is located on chromosome 2 q37.3 in humans that can be alternatively spliced into variants resulting in GPR35a or GPR35b. GPR35a encodes for 309 amino acids whereas GPR35b results in a longer N-terminal domain by 31 amino acids (14). Although GPR35b is rather associated with carcinogenesis due to its expression in gastric and colon cancer cells, GPR35a and GPR35b are localized at similar cellular compartments as well as have similar pharmacology. Hence, the functional differences between the two isoforms are not clear and yet to be studied (14-17). There are orthologues of GPR35 in mouse and rat that share 73 and $72 \%$ homology with human GPR35a (hGPR35a) and, in less extensively studied non-mammalian species such as Xenopus tropicalis (amphibian) with 33\% similarity to the hGPCR35a $(18,19)$. Recently, Danio rerio (zebrafish) homolog of hGPR35 has been cloned which led to identification of two paralogs, gpr $35 a$ and gpr $35 b$, that show $\sim 26 \%$ and $24 \%$ sequence similarity to human GPR35 (20).

GPR35 is closely related to cannabinoid receptor GPR55, the nicotinic acid receptor HM74 and LPA receptors LPAR4, LPAR5 and LPAR6 (21, 22). However, GPR35 remains an orphan receptor to date, although several potential ligand candidates have been proposed (reviewed extensively below). In this context, kynurenic acid, a tryptophan metabolite, has been suggested as a putative ligand candidate for GPR35 (23). In addition to kynurenic acid, phospholipid derivates LPA species were explored for their potency to activate GPR35 due to the structural similarity of GPR35 to the LPA receptors (24). Furthermore, CXCL17, a mucosal chemokine, was shown activate GPR35 which led to the suggestion to rename GPR35 as chemokine (C-X-C motif) receptor 8 (CXCR8) (25). In the study where GPR35 was first reported, O'Dowd et al. have shown that the expression of the newly identified GPR35 is abundant in the small intestine in rats (13). Other studies reported similar expression pattern in the small intestine and colon of mice and humans. These studies also indicated significant GPR35 expression in the spleen as well as immune cells including monocytes, macrophages, and dendritic cells. On the other hand, lower levels of GPR35 were evident in the stomach, liver, and kidney. Furthermore, gpr35a expression was restricted to the zebrafish intestine at larvae stage (20).

In addition to the expression pattern of GPR35, the polymorphisms in the human gene has been investigated by genome wide association studies (26). Importantly, two SNP variants of GPR35 have been associated with IBD that led to the definition of GPR35 as an IBD risk gene $(27,28)$. Subsequently, this prompted researchers to understand the functions of GPR35 in the intestine under different physiological conditions.

\section{PHARMACOLOGY OF GPR35}

\section{Potential Endogenous Ligands Kynurenic Acid}

To understand the function of GPR35, it is crucial to delineate upstream and downstream signaling events of its activation. To this end, Wang and colleagues tested kynurenic acid's ability to activate GPR35 signaling (23). Kynurenic acid is a tryptophanderived metabolite that is mostly recognized for its roles in the central nervous system as well as anti-inflammatory properties $(23,29,30)$. Of note, higher levels of kynurenic acid is evident in serum of inflammatory bowel disease patients (31). In micromolar concentrations, kynurenic acid induces $\mathrm{Ca}^{2+}$ influx in the presence of chimeric $G$ proteins via human, mouse and rat GPR35 in Chinese hamster ovary cells (23). Furthermore, kynurenic acid led to GPR35 internalization in HeLa cells. Other studies demonstrated that GPR35 deficiency hinders the kynurenic acid-induced adhesion of human peripheral monocytes as well as ant-inflammatory gene expression in adipocytes in mice (32, 33). Nonetheless, although the potency of kynurenic acid for activating the GPR35 is relatively high in mice and rats, the concentrations of kynurenic acid required are 40- to 100- fold higher in humans (32). In addition, in other studies, kynurenic acid failed to activate human GPR35 even at high concentrations $(20,24)$. This species selectivity of kynurenic acid/GPR35 axis has led to the discussion whether the interaction is physiological, particularly in humans, which causes kynurenic acid to retain a potential endogenous ligand for GPR35 (34). 


\section{Lysophosphatidic Acid}

GPR35 has also been explored as a receptor for LPA due to its homology to other LPA receptors. Oka et al. have shown that LPA led to $\mathrm{Ca}^{2+}$ response, activation of RhoA and ERK phosphorylation in GPR35-transfected cells as well as internalization of GPR35 (24). LPA also induced a transient RhoA activation in vector-transfected control cells which was attributed to the other LPA receptors. LPA is a bioactive phospholipid derivate that is present in cell membrane but also can be produced extracellularly and activate six known GPCRs, LPAR1-6 (35). In a more recent study by Schneditz and colleagues, GPR35 deficiency prevented the LPA-induced $\mathrm{Ca}^{2+}$ signaling in bone marrow-derived macrophages (BMDMs). However, the authors hypothesized that the GPR35 deficiency might impair LPA signaling via the other LPA receptors (36). GPR35 had not been confirmed as a potential LPA receptor until our group have tested LPA in cells transfected with human GPR35 naturally coupled to an inhibitory G-protein (Gi). In this ligand identification assay, LPA lowered the cAMP signaling suggesting that LPA might induce Gi-mediated signaling (20). The ligandGPCR interaction studies are challenged by interspecies variances especially including that of GPR35. Despite this complexity, LPA/ GPR35 axis have been evident across the species, mouse and zebrafish, where LPA led to GPR35-dependent migration of macrophages as well as TNF cytokine induction marked with activation of NF-kB and ERK pathways. However, it is still not known whether GPR35 directly binds to LPA or regulates LPA signaling by interacting with and modulating the activity of its receptors.

\section{CXCL17}

CXCL17, whose expression is associated with mucosal sites, has also been proposed as an endogenous agonist of GPR35 $(25,37,38)$. Maravillas-Montero et al. determined that GPR35-transfected cells migrate towards CXCL17 $(25,37,38)$. Since CXCL17 acted on
GPR35 in nanomolar concentrations that are in a physiological range as opposed to kynurenic acid, the authors suggested to change the nomenclature of GPR35 into CXCR8. However, subsequent studies reported that CXCL17 failed to induce migratory or signaling responses in GPR35-expressing cells $(39,40)$. In addition, kynurenic acid and zaprinast reduced the effects of CXCL17 in neuropathic pain model in mice further supporting the existence of CXCL17 receptor(s) other than GPR35 (41).

In addition to kynurenic acid, LPA and CXCL17, there have been studies describing potency of other endogenously available molecules for GPR35 including 5,6-dihydroxyindole-2-carboxylic acid (DHICA), 3,3,5-triiodothyronine (reverse T3), and guanosine 3',5'-cyclic monophosphate (cGMP) (Table 1) (44, 46). However, these have not been pursued experimentally as GPR35 ligand candidates following their initial identification. In addition to attempts in deorphanizing the GPR35, it is important to mention that Schneditz et al. reported a ligand-independent basal activity of GPR35 via its interaction with the $\mathrm{Na} / \mathrm{K}$-ATPase (36).

\section{Synthetic Agonists Zaprinast}

Although there has been significant progress in identifying the putative endogenous activators of GPR35, usage of synthetic agonists also proved useful in revealing the molecular pathways involved in GPR35 activation. Of these synthetic agonist, Zaprinast a cyclic guanosine monophosphate-specific phosphodiesterase inhibitor, is one of the most widely known agonists of GPR35 (19). In contrast to the other compounds activating GPR35, zaprinast shows similar potency for human, rat, and mouse GPR35, and therefore serves as an optimal reference in studies (34).

\section{Lodoxamide}

Lodoxamide, an anti-inflammatory mast cell stabilizer, is another synthetic agonist for GPR35. However, although

TABLE 1 | Proposed agonists and antagonists of GPR35.

\begin{tabular}{|c|c|c|c|c|c|}
\hline Potential Endogenous Ligands & Source in the intestine & EC50 (human) & EC50 (mouse) & EC50 (rat) & References \\
\hline Kynurenic acid & Host, Microbiota & $217 \mu \mathrm{M}$ & Not available & $66 \mu \mathrm{M}$ & $(23,42,43)$ \\
\hline LPA & Host, Microbiota & Not available & Not available & Not available & $(20,24)$ \\
\hline CXCL17 & Host & Not available & Not available & Not available & (25) \\
\hline DHICA & Host & $22 \mu \mathrm{M}$ & Not available & Not available & (44) \\
\hline Reverse T3 & Host, Microbiota & $100 \mu \mathrm{M}$ & Not available & Not available & $(44,45)$ \\
\hline cGMP & Host & $131 \mu \mathrm{M}$ & Not available & Not available & $(46)$ \\
\hline Synthetic Agonists & & EC50 (human) & EC50 (mouse) & $\begin{array}{l}\text { EC50 } \\
\text { (rat) }\end{array}$ & References \\
\hline Zaprinast & & $2-8 \mu \mathrm{M}$ & $1 \mu \mathrm{M}$ & $100 \mathrm{nM}$ & $(19,42)$ \\
\hline Lodoxamide & & $4 \mathrm{nM}$ & Not available & $13 \mathrm{nM}$ & $(47)$ \\
\hline Pamoic acid & & $30-50 \mathrm{nM}$ & No response & $>100 \mu \mathrm{M}$ & $(17,42)$ \\
\hline Amlexanox & & Not available & Not assessed & Not available & $(48,49)$ \\
\hline Bufrolin & & $13 \mathrm{nM}$ & Not available & $10 \mathrm{nM}$ & $(47)$ \\
\hline Compound 1 & & $26 \mathrm{nM}$ & $17 \mu \mathrm{M}$ & $8 \mu \mathrm{M}$ & (50) \\
\hline Cromolyn disodium & & Not available & Not available & Not available & $(42,49)$ \\
\hline 6-bromo-8-(4-methoxybenzamido)-4-oxo-4H-chromene-2-carboxylic acid & & Not available & Not assessed & Not available & $(51)$ \\
\hline Antagonists & & $\begin{array}{l}\text { IC50 } \\
\text { (human) }\end{array}$ & $\begin{array}{l}\text { IC50 } \\
\text { (mouse) }\end{array}$ & $\begin{array}{l}\text { IC50 } \\
\text { (rat) }\end{array}$ & References \\
\hline ML-145 & & $\sim 25 \mathrm{nM}$ & No response & No response & $(42)$ \\
\hline CID2745687 & & $\sim 200 \mathrm{nM}$ & No response & No response & $(17,42)$ \\
\hline ML-194 & & $\sim 200 \mathrm{nM}$ & Not assessed & Not assessed & $(52)$ \\
\hline
\end{tabular}


potency of lodoxamide is high for human and rat GPR35, it is 100 -fold lower for the mouse orthologue $(47,53)$. Nevertheless, lodoxamide has shown to be protective in hepatic fibrosis model in mice which was reversed by a GPR35 antagonist (53). However, due to the concerns over lodoxamide's low potency for mouse GPR35, it remains controversial whether this effect is caused by direct activity of GPR35 or whether there are other molecular pathways involved.

Other synthetic agonists of GPR35 include amlexanox, bufrolin, compound 1, pamoic acid, cromolyn disodium and, 6-bromo-8-(4-methoxybenzamido)-4-oxo-4H-chromene-2carboxylic acid (Table 1). However, most of these compounds either were only tested on human GPR35 expressing cells but not rodent orthologues or have low potencies in the latter species, limiting their usage in rodent studies $(18,48-51)$.

\section{Antagonists}

Receptor antagonists, by definition, are ligands that lead to inhibition of the activity of a receptor. They are crucial for functional studies as well as for investigating protein-protein interactions of receptors. ML-145 is one of the described GPR35 antagonists. It has a higher binding capacity for human GPR35 than mouse and rat orthologues and therefore have been rather used for in vitro settings rather than rodent models (42). Similar results were obtained for CID2745687 where both antagonists led to effective inhibition of agonist activities of zaprinast and cromolyn disodium for human GPR35. On the other hand, in this study, neither ML-145 nor CID2745687 have shown antagonism for rodent orthologues of GPR35. Interestingly, Zhao et al. found that CID2745687 is able to inhibit pamoic acid induced GPR35 activation (17). In addition, CID2745687 antagonized kynurenic acid in mouse astrocytes and interfered with pamoic acid-mediated wound repair in young adult mouse colon epithelium cells $(54,55)$. Lastly, ML-194 has also been introduced as a GPR35 antagonist which remains to be confirmed (52).

\section{RISK VARIANTS OF GPR35}

Genome-wide association studies (GWAS) identified 70 SNPs in the coding region of GPR35 gene and the intergenic regions surrounding it. Six of these SNPs have been associated with increased risk of immune-related diseases (Table 2) $(26,69)$. These diseases include IBD, both ulcerative colitis and Crohn's disease, as well as primary sclerosing cholangitis (PSC) $(27,28)$. Among the IBD-associated SNPs, the rs3749171 variant that causes a threonine to methionine transition in the transmembrane III, T108M, is the most extensively studied. Schneditz and colleagues showed that this variant is hypermorphic leading to hyperactivation of GPR35 (36). In this study, GPR35 T108M resulted in increased proliferation and metabolism in BMDMs and intestinal epithelial cells. In addition, another study from the same group demonstrated that macrophages carrying the T108M have enhanced VEGF and CXCL-8 production as opposed to the reduced levels in GPR35deficient cells further reinforcing the hyperactivity caused by the variant (70). In addition to these studies, we reported that T108M variant correlated with better clinical outcome in response to TNF blockers IBD patients (20). Notably, in our study, GPR35 signaling facilitated macrophage TNF responses. It is possible that the aberrant TNF resulting from the hypermorphic T108M variant contributes to IBD pathogenesis and therefore leads to a better response to anti-TNF treatment. However, this potential mechanism remains a speculation and need to be studied more extensively. The T108M variant did not affect the agonist potencies for GPR35 profoundly, therefore, the mechanism by which the GPR35 T108M drives the hyperactivation remains unknown (47). The second IBD-associated SNP in GPR35 is rs4676410 which is an upstream intron variant causing a cytosine to thymine substitution. Although rs4676410 has a higher prevalence than T108M (Table 3), its function remains to be studied to date. Nevertheless, it is known that it does not cause a change in GPR35 tissue expression in IBD patients (27).

\section{GPR35 IN INTESTINAL HEALTH AND DISEASE}

IBD is a collective term to define chronic inflammatory conditions in the gastrointestinal tract including $\mathrm{CD}$ and $\mathrm{UC}$. Patients with IBD experience a severely compromised quality of life with symptoms diarrhea, weight loss, abdominal pain, and are more susceptible to colorectal cancer (71). Current IBD treatment options pose a significant burden on the health system due to high costs and resource exhaustion. There is an increasing prevalence for IBD globally particularly in western countries due to the urbanization of life style (72).

The abundant expression of GPR35 in the intestine and its IBDassociated variants give hints towards an important physiological function for GPR35 in the gut. To explore this possibility,

TABLE 2 | Risk variants of GPR35 associated with diseases.

\begin{tabular}{|c|c|c|c|c|c|c|}
\hline Variant ID & Variant type & Position (ch2): & Substitution & MAF & Linked Diseases & References \\
\hline rs4676410 & Intron & 240624322 & $G>A$ & 0.272 & Ankylosing spondylitis, IBD, PSC, systemic lupus erythematosus & $(27,28,56-59)$ \\
\hline rs3749171 & Missense & 240630275 & $\mathrm{C}>\mathrm{T}(\mathrm{T} 108 \mathrm{M})$ & 0.151 & $C D, \cup C$ & $(59-62)$ \\
\hline rs3749172 & Missense & 240630832 & C>A (S294R) & 0.484 & CD, coronary artery calcification & $\begin{array}{c}(63,64) \\
(65)\end{array}$ \\
\hline rs4676408 & Intergenic & 240634984 & $A>G$ & 0.4 & UC, CD & (66) \\
\hline rs4676406 & Intergenic & 240639691 & $T>G$ & 0.374 & Ankylosing spondylitis, psoriasis, PSC & $(60,67)$ \\
\hline rs34236350 & 5' UTR & 240628909 & $\mathrm{C}>\mathrm{T}$ & 0.261 & Ankylosing spondylitis, psoriasis & $(68)$ \\
\hline
\end{tabular}

MAF, Minor Allele Frequency; UTR, Untranslated region. 
TABLE 3 | Haplotype frequencies of IBD-associated GPR35 variants across all populations analyzed by LDHap (Idlink.nci.nih.gov/?tab=Idhap).

\begin{tabular}{|c|c|c|c|c|c|}
\hline \multirow{2}{*}{$\begin{array}{l}\text { RS Number } \\
\text { rs4676410 }\end{array}$} & \multirow{2}{*}{$\begin{array}{l}\text { Position (GRCh37) } \\
\text { chr2:241563739 }\end{array}$} & \multirow{2}{*}{$\begin{array}{c}\text { Allele Frequencies } \\
\mathrm{G}=0.728, \mathrm{~A}=0.272\end{array}$} & \multicolumn{3}{|c|}{ Haplotypes } \\
\hline & & & G & A & $A$ \\
\hline \multirow[t]{3}{*}{ rs3749171 } & chr2:241569692 & $\mathrm{C}=0.849, \mathrm{~T}=0.151$ & $\mathrm{C}$ & $\mathrm{T}$ & C \\
\hline & & Haplotype Count & 3636 & 744 & 617 \\
\hline & & Haplotype Frequency & 0.726 & 0.1486 & 0.1232 \\
\hline
\end{tabular}

researchers adopted several experimental approaches including in vitro culture systems and disease models using rodents. For instance, in a wound healing model, GPR35 agonists, YE120, zaprinast and pamoic acid, promoted wound repair in young adult mouse colon epithelium cells via increased migration by fibronectin expression and ERK phosphorylation (55). Furthermore, several lines of evidence from multiple studies have shown that GPR35 is protective in dextran sodium sulfate (DSS) induced colitis mouse model $(20,55,73)$. In this model, DSS causes cell death epithelial cells causing a breach in the barrier integrity and therefore dissemination of microbial products which leads to acute inflammation (74). Similar to the wound healing model, GPR35 agonists stimulated fibronectin and ERK activation in the colonic epithelium and therefore facilitated mucosal repair in the DSS model (Figure 1) (55). In subsequent studies, including ours, GPR35-deficiency led to exacerbated DSS colitis in mice as measured by clinical signs such as weight loss $(20,73)$. Nonetheless, these studies lack the genetic models required to dissect the cell specific effects of GPR35.

Our studies described the GPR35 expression across cell types in the intestine where the expression was prominent in epithelial cells as well as macrophages and dendritic cells. The macrophages in the intestine are continuously generated from the extravasating Ly6 $\mathrm{C}^{\text {high }}$ blood monocytes through their
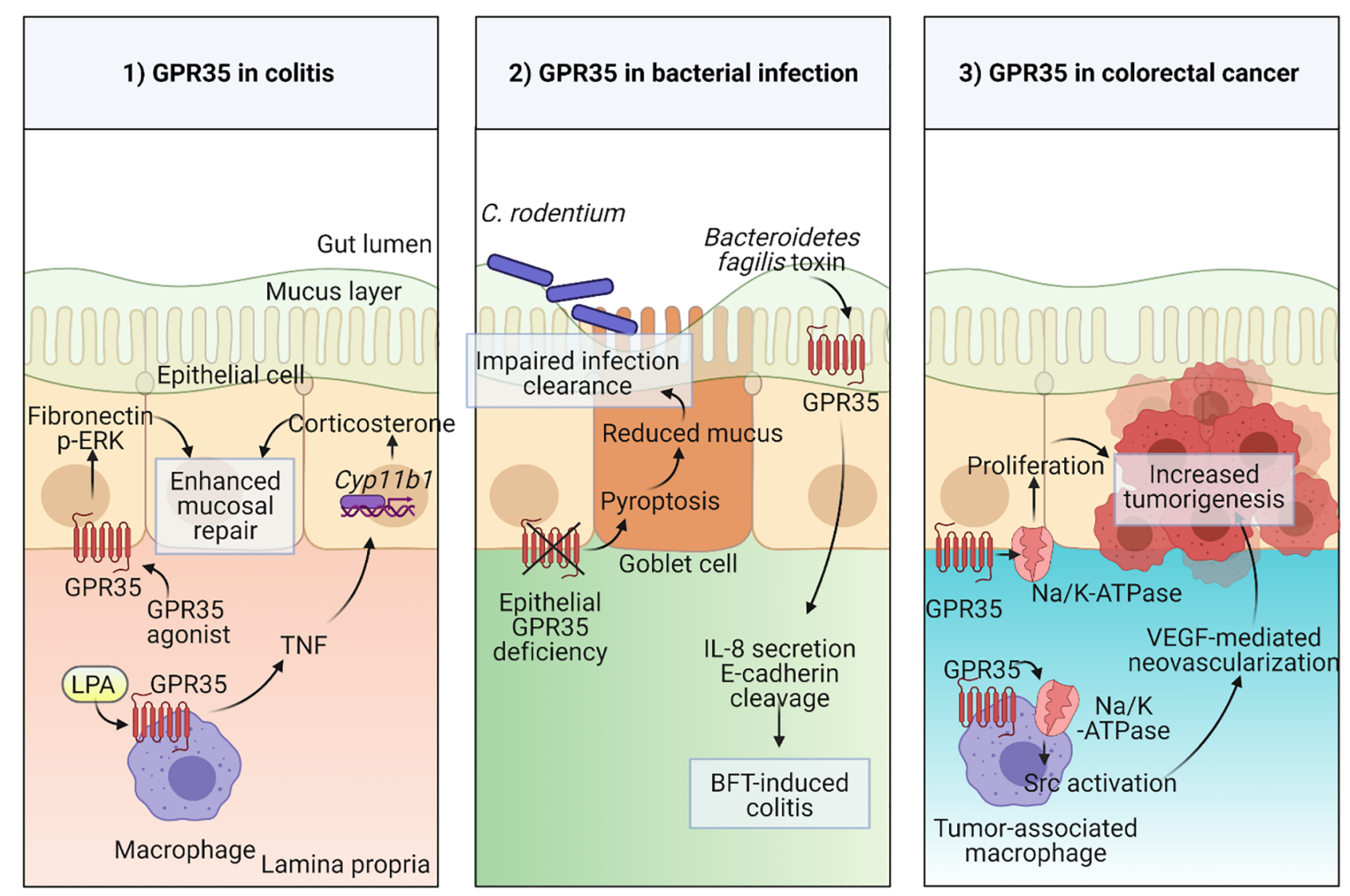

FIGURE 1 | Physiological functions of GPR35 in the intestine 1) Macrophage expressed GPR35 induces TNF accompanied by transcription of Cyp11b1 encoding for steroidogenic enzyme $11 \beta$-hydroxylase in epithelial cells during colitis. In a second mechanism, epithelial GPR35 promotes mucosal repair through ERK and fibronectin-mediated proliferation. 2) Disruption of GPR35 signaling in epithelial cells leads to pyroptosis in goblet cells resulting in reduced mucus production and therefore an impaired mucosal barrier integrity which leads to increased susceptibility to C. rodentium infection. GPR35 serves as a sensor in Bacteroidetes fragilis toxin (BFT)-induced colitis. 3) GPR35 interaction with Na/K-ATPase pump induces Src activation in both epithelial cells and tumor-associated macrophages (TAMs) in colorectal cancer model via increased proliferation in epithelial cells and neovascularization in response to TAM-derived VEGF. Created with BioRender.com. 
intermediates (75). They are vital for the maintenance of tolerance at the steady state and search the lumen for antigens by extending their dendrites between epithelial cells (76-78). On the other hand, they can also contribute to inflammatory conditions by producing pro-inflammatory cytokines including TNF (79). Interestingly, in the DSS colitis model, macrophagespecific GPR35 deletion led to elevated inflammation which was accompanied by reduced TNF responses in macrophages as well as intestinal corticosterone production (Figure 1) (20). TNF is widely known for its pro-inflammatory effects and its clinically routine use as a target in IBD treatment strategies $(80,81)$. Nevertheless, it can also play an anti-inflammatory role through corticosterone production in intestinal epithelial cells which is in line with our experimental findings $(82,83)$. In a more recent study, Pagano et al. revealed that macrophage-expressed GPR35 promotes neoangiogenesis via VEGF production and therefore tumor growth in colitis associated and spontaneous models of colon cancer in mice (70). Since neovascularization is not only involved in cancer but also in IBD, this study potentially highlights yet another mechanism by which the GPR35 signaling in macrophages plays a role in IBD pathogenesis (84).

The physiological relevance of epithelial GPR35 in the gut has also been the focus of several studies, since GPR35 is strongly expressed in intestinal epithelial cells (20). As an example, a study from our group explored the role for GPR35 in goblet cell function at the steady state and during Citrobacter rodentium infection (85). Deficiency of GPR35 in epithelial cells leads to a decrease in goblet cell numbers and Muc2 expression due to enhanced pyroptosis of goblet cells. Pyroptosis a cell death mechanism where the active caspase- 1 and caspase- 11 cleave gasdermin D causing pore formation in the cell membrane (86). By inducing pyroptosis, epithelial GPR35 deficiency led to compromised epithelial barrier and therefore susceptibility to Citrobacter rodentium infection (Figure 1). On the other hand, a recent study has shown that epithelial GPR35 is crucial in sensing the enterotoxigenic Bacteroides fragilis toxin (BFT) and initiates an immune response against it (Figure 1) (87). Therefore, as opposed to the Citrobacter rodentium infection model, epithelial GPR35 deficiency led to protection from BFTinduced colitis. Together, these two studies emphasize that the role of GPR35 signaling in epithelial cells is context-dependent in bacterial infections. Lastly, Schneditz and colleagues examined the physiological relevance of epithelial GPR35 signaling in

\section{REFERENCES}

1. Kamada N, Seo SU, Chen GY, Nunez G. Role of the Gut Microbiota in Immunity and Inflammatory Disease. Nat Rev Immunol (2013) 13:321-35. doi: $10.1038 /$ nri3430

2. Thoo L, Noti M, Krebs P. Keep Calm: The Intestinal Barrier at the Interface of Peace and War. Cell Death Dis (2019) 10:849. doi: 10.1038/s41419-019-2086-z

3. Kim D, Zeng MY, Nunez G. The Interplay Between Host Immune Cells and Gut Microbiota in Chronic Inflammatory Diseases. Exp Mol Med (2017) 49: e339. doi: 10.1038/emm.2017.24

4. Molodecky NA, Soon IS, Rabi DM, Ghali WA, Ferris M, Chernoff G, et al. Increasing Incidence and Prevalence of the Inflammatory Bowel Diseases spontaneous colon cancer model in mice (Figure 1) (36). Deletion of epithelial GPR35 led to reduced proliferation and tumor burden in this model, showing that in GPR35 contributes to cell turn over in epithelial cells during tumorigenesis.

\section{CONCLUSION}

GPR35 is an emerging GPCR in the intestinal health field with potential implications in IBD as well as colorectal cancer. GPR35 might prove useful as an intermediate player and a messenger between the microbiota and host via metabolite-sensing. However, despite the experimental evidence pointing towards potential endogenous ligand candidates for GPR35, the biochemistry of GPR35 is not fully understood. The challenges in the context of GPR35 pharmacology include orthologue selectivity, off-target effects, and lack of knowledge on interactions that are based on direct binding. To overcome these, better pharmacological assays need to be carried out to get a broader overview of the GPR35 signaling.

In this review, we summarized the recent advances in understanding the physiological functions of GPR35 and its IBD-associated risk variant T108M particularly in intestinal macrophages and epithelial cells. However, before GPR35 can be considered as a pharmaceutical target for the treatment of intestinal diseases, more studies are needed to elucidate the mechanisms governed by GPR35 signaling.

\section{AUTHOR CONTRIBUTIONS}

$\mathrm{JN}$ and $\mathrm{BK}$ conceived the content and structure of the manuscript. BK drafted the figures and JN, BK, and HM wrote the text. All authors contributed to the article and revised the final version.

\section{FUNDING}

The SNSF grant $310030 \_175548$ to JN supported this manuscript's writing.

With Time, Based on Systematic Review. Gastroenterology (2012) 142:46-54. doi: 10.1053/j.gastro.2011.10.001

5. Lee D, Albenberg L, Compher C, Baldassano R, Piccoli D, Lewis JD, et al. Diet in the Pathogenesis and Treatment of Inflammatory Bowel Diseases. Gastroenterology (2015) 148:1087-106. doi: 10.1053/j.gastro.2015.01.007

6. Spooren CE, Pierik MJ, Zeegers MP, Feskens EJ, Masclee AA, Jonkers DM. Review Article: The Association of Diet With Onset and Relapse in Patients With Inflammatory Bowel Disease. Aliment Pharmacol Ther (2013) 38:117287. doi: 10.1111/apt.12501

7. Ananthakrishnan AN, Khalili H, Konijeti GG, Higuchi LM, de Silva P, Korzenik JR, et al. A Prospective Study of Long-Term Intake of Dietary Fiber and Risk of Crohn's Disease and Ulcerative Colitis. Gastroenterology (2013) 145:970-7. doi: 10.1053/j.gastro.2013.07.050 
8. Ananthakrishnan AN, Khalili H, Konijeti GG, Higuchi LM, de Silva P, Fuchs CS, et al. Long-Term Intake of Dietary Fat and Risk of Ulcerative Colitis and Crohn's Disease. Gut (2014) 63:776-84. doi: 10.1136/gutjnl-2013-305304

9. Melhem H, Kaya B, Ayata CK, Hruz P, Niess JH. Metabolite-Sensing G Protein-Coupled Receptors Connect the Diet-Microbiota-Metabolites Axis to Inflammatory Bowel Disease. Cells (2019) 8:450. doi: 10.3390/cells8050450

10. Correa-Oliveira R, Fachi JL, Vieira A, Sato FT, Vinolo MA. Regulation of Immune Cell Function by Short-Chain Fatty Acids. Clin Transl Immunol (2016) 5:e73. doi: 10.1038/cti.2016.17

11. Singh N, Gurav A, Sivaprakasam S, Brady E, Padia R, Shi H, et al. Activation of Gpr109a, Receptor for Niacin and the Commensal Metabolite Butyrate, Suppresses Colonic Inflammation and Carcinogenesis. Immunity (2014) 40:128-39. doi: 10.1016/j.immuni.2013.12.007

12. Smith PM, Howitt MR, Panikov N, Michaud M, Gallini CA, Bohlooly YM, et al. The Microbial Metabolites, Short-Chain Fatty Acids, Regulate Colonic Treg Cell Homeostasis. Science (2013) 341:569-73. doi: 10.1126/science.1241165

13. O'Dowd BF, Nguyen T, Marchese A, Cheng R, Lynch KR, Heng HH, et al. Discovery of Three Novel G-Protein-Coupled Receptor Genes. Genomics (1998) 47:310-3. doi: 10.1006/geno.1998.5095

14. Okumura S, Baba H, Kumada T, Nanmoku K, Nakajima H, Nakane Y, et al. Cloning of a G-Protein-Coupled Receptor That Shows an Activity to Transform NIH3T3 Cells and is Expressed in Gastric Cancer Cells. Cancer Sci (2004) 95:131-5. doi: 10.1111/j.1349-7006.2004.tb03193.x

15. Guo J, Williams DJ, Puhl HL3rd, Ikeda SR. Inhibition of N-Type Calcium Channels by Activation of GPR35, an Orphan Receptor, Heterologously Expressed in Rat Sympathetic Neurons. J Pharmacol Exp Ther (2008) 324:342-51. doi: 10.1124/jpet.107.127266

16. Ali H, AbdelMageed M, Olsson L, Israelsson A, Lindmark G, Hammarstrom ML, et al. Utility of G Protein-Coupled Receptor 35 Expression for Predicting Outcome in Colon Cancer. Tumour Biol (2019) 41:1010428319858885. doi: $10.1177 / 1010428319858885$

17. Zhao P, Sharir H, Kapur A, Cowan A, Geller EB, Adler MW, et al. Targeting of the Orphan Receptor GPR35 by Pamoic Acid: A Potent Activator of Extracellular Signal-Regulated Kinase and Beta-Arrestin2 With Antinociceptive Activity. Mol Pharmacol (2010) 78:560-8. doi: 10.1124/ mol.110.066746

18. Quon T, Lin LC, Ganguly A, Tobin AB, Milligan G. Therapeutic Opportunities and Challenges in Targeting the Orphan G Protein-Coupled Receptor Gpr35. ACS Pharmacol Transl Sci (2020) 3:801-12. doi: 10.1021/ acsptsci.0c00079

19. Taniguchi Y, Tonai-Kachi H, Shinjo K. Zaprinast, a Well-Known Cyclic Guanosine Monophosphate-Specific Phosphodiesterase Inhibitor, is an Agonist for GPR35. FEBS Lett (2006) 580:5003-8. doi: 10.1016/ j.febslet.2006.08.015

20. Kaya B, Donas C, Wuggenig P, Diaz OE, Morales RA, Melhem H, et al. Lysophosphatidic Acid-Mediated GPR35 Signaling in CX3CR1(+) Macrophages Regulates Intestinal Homeostasis. Cell Rep (2020) 32:107979. doi: 10.1016/j.celrep.2020.107979

21. Fredriksson R, Lagerstrom MC, Lundin LG, Schioth HB. The G-ProteinCoupled Receptors in the Human Genome Form Five Main Families. Phylogenetic Analysis, Paralogon Groups, and Fingerprints. Mol Pharmacol (2003) 63:1256-72. doi: 10.1124/mol.63.6.1256

22. Vassilatis DK, Hohmann JG, Zeng H, Li F, Ranchalis JE, Mortrud MT, et al. The G Protein-Coupled Receptor Repertoires of Human and Mouse. Proc Natl Acad Sci USA (2003) 100:4903-8. doi: 10.1073/pnas.0230374100

23. Wang J, Simonavicius N, Wu X, Swaminath G, Reagan J, Tian H, et al. Kynurenic Acid as a Ligand for Orphan G Protein-Coupled Receptor GPR35. J Biol Chem (2006) 281:22021-8. doi: 10.1074/jbc.M603503200

24. Oka S, Ota R, Shima M, Yamashita A, Sugiura T. GPR35 Is a Novel Lysophosphatidic Acid Receptor. Biochem Biophys Res Commun (2010) 395:232-7. doi: 10.1016/j.bbrc.2010.03.169

25. Maravillas-Montero JL, Burkhardt AM, Hevezi PA, Carnevale CD, Smit MJ, Zlotnik A. Cutting Edge: GPR35/CXCR8 Is the Receptor of the Mucosal Chemokine CXCL17. J Immunol (2015) 194:29-33. doi: 10.4049/jimmunol.1401704

26. Mackenzie AE, Lappin JE, Taylor DL, Nicklin SA, Milligan G. GPR35 as a Novel Therapeutic Target. Front Endocrinol (Lausanne) (2011) 2:68. doi: $10.3389 /$ fendo.2011.00068
27. Imielinski M, Baldassano RN, Griffiths A, Russell RK, Annese V, Dubinsky M, et al. Common Variants at Five New Loci Associated With Early-Onset Inflammatory Bowel Disease. Nat Genet (2009) 41:1335-40. doi: 10.1038/ ng.489

28. Ellinghaus D, Folseraas T, Holm K, Ellinghaus E, Melum E, Balschun T, et al. Genome-Wide Association Analysis in Primary Sclerosing Cholangitis and Ulcerative Colitis Identifies Risk Loci at GPR35 and TCF4. Hepatology (2013) 58:1074-83. doi: 10.1002/hep.25977

29. Vecsei L, Szalardy L, Fulop F, Toldi J. Kynurenines in the CNS: Recent Advances and New Questions. Nat Rev Drug Discov (2013) 12:64-82. doi: $10.1038 / \mathrm{nrd} 3793$

30. Fallarini S, Magliulo L, Paoletti T, de Lalla C, Lombardi G. Expression of Functional GPR35 in Human iNKT Cells. Biochem Biophys Res Commun (2010) 398:420-5. doi: 10.1016/j.bbrc.2010.06.091

31. Forrest CM, Youd P, Kennedy A, Gould SR, Darlington LG, Stone TW. Purine, Kynurenine, Neopterin and Lipid Peroxidation Levels in Inflammatory Bowel Disease. J BioMed Sci (2002) 9:436-42. doi: 10.1007/ BF02256538

32. Barth MC, Ahluwalia N, Anderson TJ, Hardy GJ, Sinha S, Alvarez-Cardona JA, et al. Kynurenic Acid Triggers Firm Arrest of Leukocytes to Vascular Endothelium Under Flow Conditions. J Biol Chem (2009) 284:19189-95. doi: 10.1074/jbc.M109.024042

33. Agudelo LZ, Ferreira DMS, Cervenka I, Bryzgalova G, Dadvar S, Jannig PR, et al. Kynurenic Acid and Gpr35 Regulate Adipose Tissue Energy Homeostasis and Inflammation. Cell Metab (2018) 27:378-92.e5. doi: 10.1016/j.cmet.2018.01.004

34. Milligan G. Orthologue Selectivity and Ligand Bias: Translating the Pharmacology of GPR35. Trends Pharmacol Sci (2011) 32:317-25. doi: 10.1016/j.tips.2011.02.002

35. Ye X, Chun J. Lysophosphatidic Acid (LPA) Signaling in Vertebrate Reproduction. Trends Endocrinol Metab (2010) 21:17-24. doi: 10.1016/ j.tem.2009.08.003

36. Schneditz G, Elias JE, Pagano E, Zaeem Cader M, Saveljeva S, Long K, et al. GPR35 Promotes Glycolysis, Proliferation, and Oncogenic Signaling by Engaging With the Sodium Potassium Pump. Sci Signal (2019) 12:eaau9048. doi: 10.1126/scisignal.aau9048

37. Lee WY, Wang CJ, Lin TY, Hsiao CL, Luo CW. CXCL17, an Orphan Chemokine, Acts as a Novel Angiogenic and Anti-Inflammatory Factor. Am J Physiol Endocrinol Metab (2013) 304:E32-40. doi: 10.1152/ ajpendo.00083.2012

38. Burkhardt AM, Tai KP, Flores-Guiterrez JP, Vilches-Cisneros N, Kamdar K, Barbosa-Quintana O, et al. CXCL17 is a Mucosal Chemokine Elevated in Idiopathic Pulmonary Fibrosis That Exhibits Broad Antimicrobial Activity. J Immunol (2012) 188:6399-406. doi: 10.4049/jimmunol.1102903

39. Binti Mohd Amir NAS, Mackenzie AE, Jenkins L, Boustani K, Hillier MC, Tsuchiya T, et al. Evidence for the Existence of a CXCL17 Receptor Distinct From GPR35. J Immunol (2018) 201:714-24. doi: 10.4049/jimmunol.1700884

40. Park SJ, Lee SJ, Nam SY, Im DS. GPR35 Mediates Lodoxamide-Induced Migration Inhibitory Response But Not CXCL17-Induced Migration Stimulatory Response in THP-1 Cells; Is GPR35 a Receptor for CXCL17? Br J Pharmacol (2018) 175:154-61. doi: 10.1111/bph.14082

41. Rojewska E, Ciapala K, Mika J. Kynurenic Acid and Zaprinast Diminished CXCL17-Evoked Pain-Related Behaviour and Enhanced Morphine Analgesia in a Mouse Neuropathic Pain Model. Pharmacol Rep (2019) 71:139-48. doi: 10.1016/j.pharep.2018.10.002

42. Jenkins L, Harries N, Lappin JE, MacKenzie AE, Neetoo-Isseljee Z, Southern C, et al. Antagonists of GPR35 Display High Species Ortholog Selectivity and Varying Modes of Action. J Pharmacol Exp Ther (2012) 343:683-95. doi: 10.1124/jpet.112.198945

43. Gao J, Xu K, Liu H, Liu G, Bai M, Peng C, et al. Impact of the Gut Microbiota on Intestinal Immunity Mediated by Tryptophan Metabolism. Front Cell Infect Microbiol (2018) 8:13. doi: 10.3389/fcimb.2018.00013

44. Deng H, Hu H, Fang Y. Multiple Tyrosine Metabolites are GPR35 Agonists. Sci Rep (2012) 2:373. doi: 10.1038/srep00373

45. Frohlich E, Wahl R. Microbiota and Thyroid Interaction in Health and Disease. Trends Endocrinol Metab (2019) 30:479-90. doi: 10.1016/ j.tem.2019.05.008 
46. Southern C, Cook JM, Neetoo-Isseljee Z, Taylor DL, Kettleborough CA, Merritt A, et al. Screening Beta-Arrestin Recruitment for the Identification of Natural Ligands for Orphan G-Protein-Coupled Receptors. J Biomol Screen (2013) 18:599-609. doi: 10.1177/1087057113475480

47. MacKenzie AE, Caltabiano G, Kent TC, Jenkins L, McCallum JE, Hudson BD, et al. The Antiallergic Mast Cell Stabilizers Lodoxamide and Bufrolin as the First High and Equipotent Agonists of Human and Rat GPR35. Mol Pharmacol (2014) 85:91-104. doi: 10.1124/mol.113.089482

48. Alkondon M, Pereira EF, Todd SW, Randall WR, Lane MV, Albuquerque EX. Functional G-Protein-Coupled Receptor 35 Is Expressed by Neurons in the CA1 Field of the Hippocampus. Biochem Pharmacol (2015) 93:506-18. doi: 10.1016/j.bcp.2014.12.009

49. Mackenzie AE. An Investigation of the Molecular Pharmacology of G ProteinCoupled Receptor 35. Scotland: Univeristy of Glasgow (2015).

50. Neetoo-Isseljee Z, MacKenzie AE, Southern C, Jerman J, McIver EG, Harries $\mathrm{N}$, et al. High-Throughput Identification and Characterization of Novel, Species-Selective GPR35 Agonists. J Pharmacol Exp Ther (2013) 344:56878. doi: 10.1124/jpet.112.201798

51. Funke M, Thimm D, Schiedel AC, Muller CE. 8-Benzamidochromen-4-One2-Carboxylic Acids: Potent and Selective Agonists for the Orphan G ProteinCoupled Receptor GPR35. J Med Chem (2013) 56:5182-97. doi: 10.1021/ jm $400587 \mathrm{~g}$

52. Heynen-Genel S, Dahl R, Shi S, Sauer M, Hariharan S, Sergienko E, et al. Selective GPR35 Antagonists - Probe 3, Probe Reports From the NIH Molecular Libraries Program. Bethesda (MD National Center for Biotechnology Information (US)) (2011).

53. Kim MJ, Park SJ, Nam SY, Im DS. Lodoxamide Attenuates Hepatic Fibrosis in Mice: Involvement of GPR35. Biomol Ther (Seoul) (2019) 28:92-7. doi: 10.4062/biomolther.2018.227

54. Berlinguer-Palmini R, Masi A, Narducci R, Cavone L, Maratea D, Cozzi A, et al. GPR35 Activation Reduces Ca2+ Transients and Contributes to the Kynurenic Acid-Dependent Reduction of Synaptic Activity at CA3-CA1 Synapses. PloS One (2013) 8:e82180. doi: 10.1371/journal.pone.0082180

55. Tsukahara T, Hamouda N, Utsumi D, Matsumoto K, Amagase K, Kato S. G Protein-Coupled Receptor 35 Contributes to Mucosal Repair in Mice via Migration of Colonic Epithelial Cells. Pharmacol Res (2017) 123:27-39. doi: 10.1016/j.phrs.2017.06.009

56. C. International Genetics of Ankylosing Spondylitis, Cortes A, Hadler J, Pointon JP, Robinson PC, Karaderi T, et al. Identification of Multiple Risk Variants for Ankylosing Spondylitis Through High-Density Genotyping of Immune-Related Loci. Nat Genet (2013) 45:730-8. doi: 10.1038/ng.2667

57. Kichaev G, Bhatia G, Loh PR, Gazal S, Burch K, Freund MK, et al. Leveraging Polygenic Functional Enrichment to Improve GWAS Power. Am J Hum Genet (2019) 104:65-75. doi: 10.1016/j.ajhg.2018.11.008

58. Li YR, Li J, Zhao SD, Bradfield JP, Mentch FD, Maggadottir SM, et al. MetaAnalysis of Shared Genetic Architecture Across Ten Pediatric Autoimmune Diseases. Nat Med (2015) 21:1018-27. doi: 10.1038/nm.3933

59. Liu JZ, van Sommeren S, Huang H, Ng SC, Alberts R, Takahashi A, et al. Association Analyses Identify 38 Susceptibility Loci for Inflammatory Bowel Disease and Highlight Shared Genetic Risk Across Populations. Nat Genet (2015) 47:979-86. doi: 10.1038/ng.3359

60. Ellinghaus D, Jostins L, Spain SL, Cortes A, Bethune J, Han B, et al. Analysis of Five Chronic Inflammatory Diseases Identifies $27 \mathrm{New}$ Associations and Highlights Disease-Specific Patterns at Shared Loci. Nat Genet (2016) 48:510-8. doi: $10.1038 / n g .3528$

61. Jostins L, Ripke S, Weersma RK, Duerr RH, McGovern DP, Hui KY, et al. HostMicrobe Interactions Have Shaped the Genetic Architecture of Inflammatory Bowel Disease. Nature (2012) 491:119-24. doi: 10.1038/nature11582

62. Venkateswaran S, Prince J, Cutler DJ, Marigorta UM, Okou DT, Prahalad S, et al. Enhanced Contribution of HLA in Pediatric Onset Ulcerative Colitis. Inflamm Bowel Dis (2018) 24:829-38. doi: 10.1093/ibd/izx084

63. Sun YV, Bielak LF, Peyser PA, Turner ST, Sheedy PF2nd, Boerwinkle E, et al. Application of Machine Learning Algorithms to Predict Coronary Artery Calcification With a Sibship-Based Design. Genet Epidemiol (2008) 32:35060. doi: 10.1002/gepi.20309

64. Jung S, Liu W, Baek J, Moon JW, Ye BD, Lee HS, et al. Expression Quantitative Trait Loci (eQTL) Mapping in Korean Patients With Crohn's Disease and
Identification of Potential Causal Genes Through Integration With Disease Associations. Front Genet (2020) 11:486. doi: 10.3389/fgene.2020.00486

65. Yang SK, Hong M, Oh H, Low HQ, Jung S, Ahn S, et al. Identification of Loci at 1q21 and 16q23 That Affect Susceptibility to Inflammatory Bowel Disease in Koreans. Gastroenterology (2016) 151:1096-99.e4. doi: 10.1053/j.gastro. 2016.08.025

66. de Lange KM, Moutsianas L, Lee JC, Lamb CA, Luo Y, Kennedy NA, et al. Genome-Wide Association Study Implicates Immune Activation of Multiple Integrin Genes in Inflammatory Bowel Disease. Nat Genet (2017) 49:256-61. doi: $10.1038 /$ ng. 3760

67. Anderson G, Maes M, Berk M. Inflammation-Related Disorders in the Tryptophan Catabolite Pathway in Depression and Somatization. Adv Protein Chem Struct Biol (2012) 88:27-48. doi: 10.1016/B978-0-12-3983145.00002-7

68. Astle WJ, Elding H, Jiang T, Allen D, Ruklisa D, Mann AL, et al. The Allelic Landscape of Human Blood Cell Trait Variation and Links to Common Complex Disease. Cell (2016) 167:1415-29.e19. doi: 10.1016/j.cell.2016.10.042

69. Horikawa Y, Oda N, Cox NJ, Li X, Orho-Melander M, Hara M, et al. Genetic Variation in the Gene Encoding Calpain-10 is Associated With Type 2 Diabetes Mellitus. Nat Genet (2000) 26:163-75. doi: 10.1038/79876

70. Pagano E, Elias JE, Schneditz G, Saveljeva S, Holland LM, Borrelli F, et al. Activation of the GPR35 Pathway Drives Angiogenesis in the Tumour Microenvironment. Gut (2021) gutjnl-2020-323363. doi: 10.1136/gutjnl2020-323363

71. Kim ER, Chang DK. Colorectal Cancer in Inflammatory Bowel Disease: The Risk, Pathogenesis, Prevention and Diagnosis. World J Gastroenterol (2014) 20:9872-81. doi: $10.3748 /$ wjg.v20.i29.9872

72. Kaplan GG, Windsor JW. The Four Epidemiological Stages in the Global Evolution of Inflammatory Bowel Disease. Nat Rev Gastroenterol Hepatol (2021) 18:56-66. doi: 10.1038/s41575-020-00360-x

73. Farooq SM, Hou Y, Li H, O'Meara M, Wang Y, Li C, et al. Disruption of GPR35 Exacerbates Dextran Sulfate Sodium-Induced Colitis in Mice. Dig Dis Sci (2018) 63:2910-22. doi: 10.1007/s10620-018-5216-z

74. Laroui H, Ingersoll SA, Liu HC, Baker MT, Ayyadurai S, Charania MA, et al. Dextran Sodium Sulfate (DSS) Induces Colitis in Mice by Forming NanoLipocomplexes With Medium-Chain-Length Fatty Acids in the Colon. PloS One (2012) 7:e32084. doi: 10.1371/journal.pone.0032084

75. Bain CC, Bravo-Blas A, Scott CL, Perdiguero EG, Geissmann F, Henri S, et al. Constant Replenishment From Circulating Monocytes Maintains the Macrophage Pool in the Intestine of Adult Mice. Nat Immunol (2014) 15:929-37. doi: $10.1038 /$ ni.2967

76. Hadis U, Wahl B, Schulz O, Hardtke-Wolenski M, Schippers A, Wagner N, et al. Intestinal Tolerance Requires Gut Homing and Expansion of FoxP3+ Regulatory T Cells in the Lamina Propria. Immunity (2011) 34:237-46. doi: 10.1016/j.immuni.2011.01.016

77. Maheshwari A, Kelly DR, Nicola T, Ambalavanan N, Jain SK, Murphy-Ullrich J, et al. TGF-Beta2 Suppresses Macrophage Cytokine Production and Mucosal Inflammatory Responses in the Developing Intestine. Gastroenterology (2011) 140:242-53. doi: 10.1053/j.gastro.2010.09.043

78. Niess JH, Brand S, Gu X, Landsman L, Jung S, McCormick BA, et al. CX3CR1Mediated Dendritic Cell Access to the Intestinal Lumen and Bacterial Clearance. Science (2005) 307:254-8. doi: 10.1126/science.1102901

79. Bain CC, Mowat AM. The Monocyte-Macrophage Axis in the Intestine. Cell Immunol (2014) 291:41-8. doi: 10.1016/j.cellimm.2014.03.012

80. Hanauer SB, Feagan BG, Lichtenstein GR, Mayer LF, Schreiber S, Colombel JF, et al. Maintenance Infliximab for Crohn's Disease: The ACCENT I Randomised Trial. Lancet (2002) 359:1541-9. doi: 10.1016/S0140-6736(02) 08512-4

81. Targan SR, Hanauer SB, van Deventer SJ, Mayer L, Present DH, Braakman T, et al. A Short-Term Study of Chimeric Monoclonal Antibody Ca2 to Tumor Necrosis Factor Alpha for Crohn's Disease. Crohn's Disease Ca2 Study Group. N Engl J Med (1997) 337:1029-35. doi: 10.1056/NEJM199710093371502

82. Noti M, Corazza N, Mueller C, Berger B, Brunner T. TNF Suppresses Acute Intestinal Inflammation by Inducing Local Glucocorticoid Synthesis. J Exp Med (2010) 207:1057-66. doi: 10.1084/jem.20090849

83. Naito Y, Takagi T, Handa O, Ishikawa T, Nakagawa S, Yamaguchi T, et al. Enhanced Intestinal Inflammation Induced by Dextran Sulfate Sodium in 
Tumor Necrosis Factor-Alpha Deficient Mice. J Gastroenterol Hepatol (2003) 18:560-9. doi: 10.1046/j.1440-1746.2003.03034.x

84. Scaldaferri F, Vetrano S, Sans M, Arena V, Straface G, Stigliano E, et al. VEGF-A Links Angiogenesis and Inflammation in Inflammatory Bowel Disease Pathogenesis. Gastroenterology (2009) 136:585-95.e5. doi: 10.1053/j.gastro.2008.09.064

85. Melhem H, Kaya B, Kaymak T, Wuggenig P, Flint E, Roux J, et al. Epithelial GPR35 Protects From Citrobacter Rodentium Infection by Preserving Goblet Cells and Mucosal Barrier Integrity. bioRxiv (2021) 2021.03.27.437264. doi: 10.1101/2021.03.27.437264

86. Zhu S, Ding S, Wang P, Wei Z, Pan W, Palm NW, et al. Nlrp9b Inflammasome Restricts Rotavirus Infection in Intestinal Epithelial Cells. Nature (2017) 546:667-70. doi: 10.1038/nature22967

87. Boleij A, Fathi P, Dalton W, Park B, Wu X, Huso D, et al. G-Protein Coupled Receptor 35 (GPR35) Regulates the Colonic Epithelial Cell Response to Enterotoxigenic Bacteroides Fragilis. Commun Biol (2021) 4:585. doi: 10.1038/s42003-021-02014-3
Conflict of Interest: The authors declare that the research was conducted in the absence of any commercial or financial relationships that could be construed as a potential conflict of interest.

Publisher's Note: All claims expressed in this article are solely those of the authors and do not necessarily represent those of their affiliated organizations, or those of the publisher, the editors and the reviewers. Any product that may be evaluated in this article, or claim that may be made by its manufacturer, is not guaranteed or endorsed by the publisher.

Copyright (c) 2021 Kaya, Melhem and Niess. This is an open-access article distributed under the terms of the Creative Commons Attribution License (CC BY). The use, distribution or reproduction in other forums is permitted, provided the original author(s) and the copyright owner(s) are credited and that the original publication in this journal is cited, in accordance with accepted academic practice. No use, distribution or reproduction is permitted which does not comply with these terms. 